\title{
The importance of tar and nicotine in determining cigarette smoking habits
}

\author{
NICHOLAS J. WALD, MARIANNE IDLE, AND JILLIAN BOREHAM \\ From the ICRF Cancer Epidemiology and Clinical Trials Unit, University of Oxford
}

\author{
ALAN BAILEY \\ From the British United Provident Association Medical Research Department, London
}

SUMMARY Cigarette consumption and inhaling, assessed using carboxyhaemoglobin levels, were studied in $\mathbf{1 7 8 6}$ men to investigate the importance of tar and nicotine as determinants of smoking habits. No prior warning was given that smoking habits would be studied. Neither nicotine nor tar yields materially influenced the number of cigarettes smoked a day. Both nicotine and tar yields were negatively associated with inhaling $(p<0.001)$ but after allowing for either of the two yields the effect of the other on inhaling was no longer statistically significant. There was, therefore, no indication as to whether nicotine or tar was the more important determinant of smoking habit.

The factors that determine the numbers of cigarettes a person smokes each day and the extent to which he inhales cigarette smoke are little understood but they are likely to be complex. The nicotine yield of cigarettes has often been suggested as an important determinant of smoking habits, the idea being that as the nicotine yield increases fewer cigarettes are smoked or the extent of inhaling is reduced, or both. However, nicotine yields are highly correlated with tar yields, and it is possible that people smoke as much for the flavour of the tar as for the neuropharmacological effect of the nicotine. To investigate the importance of tar and nicotine as determinants of smoking habits we studied cigarette consumption and inhaling in relation to the tar and nicotine yields of cigarettes smoked by a population of men attending a medical screening centre in London.

\section{Methods}

The study population consisted of men aged 35-64 who completed a questionnaire on their smoking habits and provided blood for a carboxyhaemoglobin $(\mathrm{COHb})$ estimation. They had no prior warning that their smoking habits would be investigated. Carbon monoxide $(\mathrm{CO})$ yields of the cigarettes smoked were obtained from the Tobacco Advisory Council. Tar and nicotine yields were obtained from tables published by the United Kingdom health departments.

\section{Results}

Table 1 shows that the number of cigarettes smoked a day was statistically significantly related to the nicotine yields, but the effect was very small indeed. Table 2 shows, in a similar way, that there was no significant relationship between the mean number smoked a day and the tar yields.

The COHb inhaling index, ${ }^{1}$ an objective measure of tobacco smoke intake for each cigarette smoked, decreased progressively as the nicotine increased (Table 1). This trend was statistically highly significant; men who smoked cigarettes in the lowest nicotine yield category $(0 \cdot 3-0.8 \mathrm{mg} /$ cigarette $)$ inhaled 33\% more than the average for all men, while those in the highest nicotine yield category (1.4-3.5 $\mathrm{mg} /$ cigarette) inhaled $17 \%$ less. The trend was still present when the type of cigarette (plain, unventilated filter or ventilated filter) was taken into account $\left(\chi_{1}^{2} 7.71, p<0.01\right)$. Table 2 shows, in a similar way, the $\mathrm{COHb}$ inhaling index according to the tar yield of cigarettes smoked. Again, inhaling decreased progressively with increasing tar yields, and this trend also was statistically highly significant and present when the type of cigarette was taken into account $\left(\chi_{1}^{2} 8.65, p<0.005\right)$. Since the tar and nicotine yields of cigarettes are highly correlated, it is not surprising that the inhaling results in Tables 1 and 2 are similar. The greater spread of values for the relative inhaling index when grouped by tar rather than by nicotine does not necessarily mean that tar has a greater influence on inhaling than nicotine; this may have arisen by chance, or possibly because a smaller proportion of men were in the extreme tar groups than were in the extreme nicotine groups.

In spite of the quite large number (1786) of subjects studied the correlation between tar and nicotine yields was so close as to make it impossible to estimate the relative importance of each as 
Table 1 Number of cigarettes smoked a day and COHb inhaling index according to nicotine yield

\begin{tabular}{|c|c|c|c|c|c|}
\hline \multirow{2}{*}{$\begin{array}{l}\text { Nicotine yield } \\
\text { (mg/cigarette) }\end{array}$} & \multirow[b]{2}{*}{ No. of men } & \multicolumn{2}{|c|}{ No. of cigarettes smoked a day* } & \multirow{2}{*}{$\begin{array}{l}\text { COHb inhaling index ** } \\
(\% \mathrm{COHb} / \mathrm{mg} \mathrm{CO})\end{array}$} & \multirow[b]{2}{*}{ Relative inhaling index ** } \\
\hline & & Mean & $S D$ & & \\
\hline $\begin{array}{l}0.3- \\
0.9- \\
1.2- \\
1.3- \\
1.4-3.5\end{array}$ & $\begin{array}{l}409 \\
246 \\
427 \\
385 \\
319\end{array}$ & $\begin{array}{l}24 \\
25 \\
23 \\
23 \\
23\end{array}$ & $\begin{array}{l}10 \\
11 \\
10 \\
10 \\
10\end{array}$ & $\begin{array}{l}0 \cdot 278 \\
0 \cdot 211 \\
0 \cdot 187 \\
0 \cdot 187 \\
0 \cdot 174\end{array}$ & $\begin{array}{l}1.33 \\
1.01 \\
0.89 \\
0.89 \\
0.83\end{array}$ \\
\hline ALL & 1786 & 24 & 10 & 0.209 & $1 \cdot 00$ \\
\hline
\end{tabular}

* $x_{1}^{2}$ trend $5.1 \mathrm{p}<0.05$

** $\chi_{1}^{2}$ trend $40.8 \mathrm{p}<0.001$

Table 2 Number of cigarettes smoked a day and $\mathrm{COHb}$ inhaling index according to tar yield

\begin{tabular}{|c|c|c|c|c|c|}
\hline \multirow{2}{*}{$\begin{array}{l}\text { Tar yield } \\
\text { (mg/cigarette) }\end{array}$} & \multirow[b]{2}{*}{ No. of men } & \multicolumn{2}{|c|}{ No. of cigarettes smoked a day* } & \multirow{2}{*}{$\begin{array}{l}\text { COHb inhaling index ** } \\
(\% \mathrm{COHb} / \mathrm{mg} \mathrm{CO})\end{array}$} & \multirow[b]{2}{*}{ Relative inhaling index** } \\
\hline & & Mean & $S D$ & & \\
\hline $\begin{array}{l}4- \\
10- \\
18- \\
19- \\
20-34\end{array}$ & $\begin{array}{l}375 \\
348 \\
282 \\
538 \\
243\end{array}$ & $\begin{array}{l}24 \\
24 \\
24 \\
23 \\
23\end{array}$ & $\begin{array}{r}10 \\
10 \\
11 \\
10 \\
9\end{array}$ & $\begin{array}{l}0.283 \\
0.211 \\
0.201 \\
0.184 \\
0.159\end{array}$ & $\begin{array}{l}1.35 \\
1.01 \\
0.96 \\
0.88 \\
0.76\end{array}$ \\
\hline ALL & 1786 & 24 & 10 & 0.209 & 1.00 \\
\hline
\end{tabular}

" $x_{1}^{2}$ trend 3.7 NS

** $x_{1}^{2}$ trend $54.2 \mathrm{p}<0.001$

determinants of inhaling; a two-way analysis of variance indicated that after allowing for the effect of either of the two yields, inhaling was no longer significantly influenced by the other. Our results, therefore, gave no indication whether nicotine or tar was the more important determinant of inhaling.

\section{Discussion}

This study has produced three results. First, the extent of inhaling as measured by the $\mathrm{COHb}$ inhaling index was significantly related to the tar and nicotine yields of the cigarettes and this conclusion held for different types of cigarette. Secondly, neither nicotine nor tar yield was shown to influence the extent of inhaling when the other was held constant. Thirdly, as in other studies, ${ }^{2} 3$ neither nicotine nor tar yields materially influenced the number of cigarettes smoked a day. Thus smokers appear to compensate for the decreases in 'strength' of cigarettes by inhaling more rather than by increasing cigarette consumption.

Our study provides no support for the widely held view that nicotine rather than tar yield influences smoking habits. A review of the subject in $1977^{4}$ considered that the basis for the popular view had been exaggerated. Our present findings accord with this conclusion: they neither weigh against nor favour either tar or nicotine as possible influences on smoking habits.
We thank the Tobacco Advisory Council for providing the $\mathrm{CO}$ yields, the Medical Research Council for financial support and Peter Lee for helpful comments. Dr. Jillian Boreham is a Laing Research Fellow in Preventive Medicine.

Reprints from Dr. Nicholas J. Wald, ICRF Cancer Epidemiology and Clinical Trials Unit, University of Oxford, Radcliffe Infirmary, Oxford OX2 6HE.

\section{References}

${ }^{1}$ Wald NJ, Idle M, Boreham J, Bailey A. Inhaling habits among smokers of different types of cigarettes. Thorax $1980 ; 35$ (12): 925-8.

${ }^{2}$ Garfinkel L. Changes in number of cigarettes smoked compared to changes in tar and nicotine content over a 13-year period. In: Gori G, Bock F, ed. Banbury Report No. 3: A Safe Cigarette? New York: Cold Spring Harbor Laboratory, 1980.

${ }^{3}$ Russell MAH, Jarvis M, Iyer R, Feyerabend C. Relation of nicotine yield of cigarettes to blood nicotine concentrations in smokers. Br Med J 1980; 280: 972-6.

4 Anonymous. Do people smoke for nicotine? Br Med J 1977; ii: 1041-2. 